Review

\title{
Promising Effects of Beta-Glucans on Metabolism and on the Immune Responses: Review Article
}

\author{
${ }^{1}$ Viviam de Oliveira Silva, ${ }^{2}$ Natália Oliveira de Moura, \\ ${ }^{3}$ Larissa Jahnel Rodrigues de Oliveira, ${ }^{4}$ Ana Paula Peconick and ${ }^{5}$ Luciano José Pereira \\ ${ }^{1}$ Posdoc fellow, Veterinary Medicine Graduate Program, Federal Universityof Lavras, Lavras, Brazil \\ ${ }^{2}$ PhD student, Veterinary Medicine Graduate Program, Federal University of Lavras, Lavras, Brazil \\ ${ }^{3}$ Undergraduate student, Veterinary Medicine School, Federal University of Lavras, Lavras, Brazil \\ ${ }^{4}$ Professor of Immunology, Department of Veterinary Medicine, Federal University of Lavras, Lavras, Brazil \\ ${ }^{5}$ Professor of Physiology, Department of Health Sciences, Federal University of Lavras, Lavras, Brazil
}

Article history

Received: 15-11-2016

Revised: 28-01-2017

Accepted: 29-03-2017

Corresponding Author:

Luciano José Pereira

Professor of Physiology,

Department of Health Sciences,

Federal University of Lavras,

Lavras, Brazil

E-mail: lucianojosepereira@dsa.ufla.br

\begin{abstract}
A public health issue, Diabetes mellitus, affects millions of people around the globe. Ingestion of foods with a low glycemic index fiber-rich meals-such as beta-glucans, is increasing as an important alternative for diabetes control. These compounds act reducing parameters such as blood glucose, cholesterol and triglycerides, by decreasing the absorption of glucose and lipids by enterocytes and eventually promote weight loss. Beta-glucans are also described as immunomodulatory agents by stimulating phagocytosis and the production of pro-inflammatory cytokines, increasing host resistance to viral, bacterial, fungal and parasitic infections; or production of anti-inflammatory cytokinesto return homeostasis after an immune response. Besides, some studies are also evidencing anti-tumoral activity. Beta-glucans main effect depends on their origin-yeast, plants or bacteria. Reports of collateral effects and/or toxicity associated with the use of beta-glucans are rare, which contribute to consider this compound for inclusion in a range of therapies. This review aims to evaluate the most different effects of beta-glucans in metabolic and immune systems, discussing its advantages and limitations.
\end{abstract}

Keywords: Prebiotics, Functional Food, Glucose, Immunity

\section{Introduction}

The interest in the study of natural compounds, such as prebiotics, has grown exponentially in recent years. This demand is because these products may have different functions in the human body. Thus, research involving the same active ingredient that promotes pleiotropic effects is of extreme interest. In this context, appears beta-glucans.

Beta-glucans have been widely used in research for medical purposes (King et al., 2005; Sener et al., 2006; Harnack et al., 2011; Vetvicka 2011; Samuelsen et al., 2014; Chen et al., 2013; Tosh, 2013; Silva et al., 2015). These are polysaccharides from the cell wall of a variety of plants, fungi, yeasts, algae and some bacteria. Betaglucans belong to a class of compounds which are described as biological response modifiers. Apparently, they can modulate the immune system by stimulating phagocytosis and the production of pro-inflammatory cytokines (Vetvicka, 2011; Rubin-Bejerano et al., 2007). They stimulate the defense mechanisms of the host against disease instead of attacking the infectious agent, so these agents remain non-toxic to the cells of the host organism (Zeković et al., 2005).

In some cases beta-glucans can exert antiinflammatory activity (Silveira et al., 2014; Ruthes et al., 2013; Smeekens et al., 2015). According to Li et al. (2015), the association of Acetoxychavicol Acetate (ACA) with isolated beta-glucans of Aureobasidium pullulans (a type of yeast) inhibited the activation of NF$\mathrm{k} \beta$ indicating an anti-inflammatory effect from this complex ACA/beta-glucan, in vivo and in vitro. In another study, rats with chronic enteritis induced by LPS were supplemented with beta-glucans from oat (low and high molecular weight fractions). The results showed that supplementation with both fractions significantly decreased leucocytes counting: Lymphocytes $\mathrm{T}$ and B, granulocytes and lymphocytes Tc (Suchecka et al., 2015). 
The main functions of beta-glucans, related to stimulation of the immune system include increased host resistance to viral, bacterial, fungal and parasitic infections, as well as an anti-tumor adjuvant effect and prevention of the carcinogenicity (Bohn and BeMiller, 1995). Besides, they reduce plasma concentrations of glucose, cholesterol and triglycerides, despite a decrease intestinal absorption of glucose and lipids (De Paula et al., 2005; Lo et al., 2006; Vieira Lobato et al., 2015; Francelino Andrade et al., 2014). Furthermore, they are used as adjuvants in the development of various types of vaccines, by boosting the cellular immune response without the toxicity exhibited by other adjuvants (Petrovsky and Aguilar, 2004; Temizoz et al., 2016).

With this panorama, the present review aims to analyze the effects of beta-glucans in different functions (metabolic, immunomodulatory, etc.) discussing its advantages and limitations.

\section{Beta-Glucans-General Characteristics}

Wide varieties of compounds have been studied for their prebiotic attributes, so the beta-glucans are an important class of such food additives (Collins and Reid, 2016). Beta-glucans are one of the most abundant forms of structural cell wall polysaccharides of yeast (Rahar et al., 2011), plants (Volman et al., 2008) and some bacteria (Gacto et al., 2000; Chan et al., 2009). The chemical structure of beta-glucans has a central linear $\beta$ (1-3) ligation composed of glucose units linked to the main chain, which differ according to their length and branching (Xiao et al., 2004; Sonck et al., 2010). The ramifications of the glycosidic chain are highly variable and the two main groups of branch are the $\beta$ (1 $\rightarrow 4)$ and $\beta(1 \rightarrow 6)$. These ramifications distinguishes beta-glucans source, e.g., beta-glucans of fungi have side $\beta(1 \rightarrow 6)$ branches while bacteria and plants have $\beta(1 \rightarrow 4)$. The position of the branch also generally defines the biological activity that fiber (Rahar et al., 2011; Chan et al., 2009). Various methods can be used to determine the composition or structure of betaglucans. Among these, stand out the Liquid Chromatography/Mass Spectrometry (LC/MS), High Performance Liquid Chromatography (HPLC) and X-ray crystallography (Jelsma and Kreger, 1975; Rolin et al., 1992; Hanada et al., 1993).

Most beta-glucans are considered as non-digestible hydrates of carbon, so they are fermented in different degrees by the intestinal microbiota (Wang et al., 2008). Therefore, it is speculated that their immunomodulatory properties could be partially attributed to a microbial dependent effect. However, beta-glucans can bind directly to specific receptors of immune cells, suggesting a microbial independent immunomodulatory effect (Vos et al., 2007). The pharmacokinetics and pharmacodynamics of beta-glucans were studied in animal and human models (Wang et al., 2008, Chan et al., 2009). Regarding its toxicity, oral administration for four weeks of these fibers showed no toxic signs even in large quantities (Chen et al., 2013, Túrmina et al., 2012).

\section{Diabetes Mellitus and Beta-Glucans}

\section{Diabetes Mellitus}

Diabetes mellitus is a disease in which the metabolism homeostasis of carbohydrates, proteins and lipids is inadequately regulated. It can be caused by deficiency in the production of the pancreatic hormone insulin and/or insulin resistance, resulting in an increase in blood glucose level (Sunil et al., 2011). The most common signs and symptoms of diabetes mellitus are: Polyuria, polydipsia, glycosuria, polyphagia, visual changes, skin lesions, heart, mouth and kidney disorders (Seino et al., 2010). This disease is one of the main problems of public health and has been aggravated rapidly especially in developing nations. The World Health Organization estimated in 2014 that diabetes mellitus affects 422 million people worldwide. This number has increased substantially between 1980 and 2014, from 108 million people to the current 422 million, a value about four times higher (WHO, 2016).

Two main types of diabetes mellitus are recognized. Type 1 diabetes mellitus, is a deficiency in insulin production due to autoimmune destruction of pancreatic $\beta$ cells. In general, in this type of the disease, the patients are young (before 30 years old) and nonobese when the symptoms first appear and its treatment generally requires the use of insulin. In type 2 diabetes mellitus, there is resistance to insulin action. In this case the disease has polygenic inheritance origin, not yet fully defined. The pathogenesis of Type 2 diabetes mellitus is complex and involves interaction between genetic and environmental factors, especially those from obesity due to physical inactivity and excessive food intake. Oral hypoglycemic agents and/or insulin therapy often become necessary (DeFronzo, 2004; Malandrino and Smith, 2011).

The great importance of diabetes mellitus as a public health problem is the fact that most of the chronic complications of the disease is highly disabling to carry out the daily and productive activities, compromising individual's quality of the life. In addition, the treatment of the disease is extremely costly for the public health system (Fazeli Farsani et al., 2013).

The development of new alternatives for diabetes treatment is significant, especially because of the worldwide prevalence of the disease. Besides, the fact that diabetes has a chronic nature, it predisposes patients to a variety of other long term complications, especially those associated with the circulatory system 
(micro and macroangiopathies), which have complex and costly treatments. The intake of foods with a low glycemic index, for example fibers and especially beta-glucans, become an important alternative for diabetes control (Schalkwijk and Stehouwer, 2005; Francelino Andrade et al., 2014).

\section{Metabolic Activity of Beta-Glucans}

The positive effects of beta-glucans on metabolism in diabetic rats are well known (Lo et al., 2006; Kim et al., 2005). The reduction of these parameters such as blood glucose and cholesterol, may be related to physicochemical interactions of these fibers with the digestive bolus. These polysaccharides form a gelatinous layer which acts as a barrier hindering the absorption of nutrients, thus leading to a lower concentration of glucose and lipids in blood (Tappy et al., 1996; Reyna et al., 2003; Liatis et al., 2009; Choi et al., 2010; Dong et al., 2011). This layer is due to the viscosity formed in the intestinal lumen, which acts as a sieve filtering small molecules, retarding the digestion and the absorption of certain nutrients. There is also the hypothesis that this gelatinous layer delays the interaction of the starch and its digestive enzyme, causing a reduction in the absorption of carbohydrates and, consequently, the reduction of glycemia. This particularity of the beta-glucan fibers derives from its molecular weight and solubility, of their predisposition to water retention, viscosity, emulsification, fermentability, resistance to degradation by intestinal bacteria and their propensity to absorb nutrients (Battilana et al., 2001; Schneeman, 1987).

Significant improvements in glycemia, triacylglycerols and total cholesterol levels were found in diabetic rats treated with beta-glucans, explaining their beneficial effect on glucose tolerance and lipid metabolism (Miranda-Nantes et al., 2011; Gao et al., 2012). According to Lo et al. (2006), both oat and fungi beta-glucans are able to reduce rodents glycemia. The aqueous extract of beta-glucans of Agaricus blazei basidiocarpos showed anti-hyperglycemic, antihypertriglyceridemic, anti-hypercholesterolemic and anti-atherosclerotic activity in diabetic rats (Kim et al., 2005). According to Francelino Andrade et al. (2014) who conducted a systematic review using human experiments and found that ingestion of doses around 6.0 $\mathrm{g} /$ person of beta-glucans per day, for at least four weeks were sufficient to provoke improvements in the blood glucose levels and also lipid parameters of individuals with diabetes mellitus. However, glucose levels do not reach normal levels using beta-glucan alone. Low doses of beta-glucan for at least 12 weeks were also reported to promote metabolic benefits.

Vieira Lobato et al. (2015) observed in diabetesinduced rats treated with leaven beta-glucans
(Saccharomyces cerevisiae) significant reduction in plasma glucose concentration (30\%), triacylglycerols (32\%) and alanine aminotransferase (41\%). Complementarily, beta-glucans also decreased blood levels of total cholesterol (13\%), triglycerides $(17 \%)$ and glucose $(24 \%)$, in obese rats (induced by high fat diet) when compared to untreated obese animals (de Araújo et al., 2016). Reduction of total cholesterol and LDL fraction were also reported elsewhere (Tiwari and Cummins, 2011).

In addition, beta-glucans can be reduce the risk of cardiovascular and metabolic diseases through the mediation of the inflammatory process (Liu et al., 2002; Liu 2003). The hypotheses of these mechanisms have shown that beta-glucans may decrease the oxidation of glucose and lipids, promoting a healthy intestinal environment by preventing inflammation and by changing the adipocytokines in adipose tissue and also, enhancing the enterohepatic circulation of lipids and lipophilic compounds (King et al., 2005).

\section{Beta-Glucans and Body Weight}

Beta-glucans participate in physiological processes related to the metabolism of fats in the human's body. Thus, it was expected that the consumption of those fibers may also contribute to reductions in body weight (Rop et al., 2009). Observational studies showed that the ingestion of dietary fiber decreases the energy intake (Lissner et al., 1998) and that the obesity rate is lower if food intake contains an adequate amount of fiber (Kimm, 1995). Thus, an inverse correlation has been reported between the fiber intake and weight (Alfieri et al., 1995) and body mass index (Kim et al., 2006; Liu et al., 2002).

The effect of fiber on weight control is affected by the blood sugar level, which is related to hunger, insulin secretion, gastric emptying time and the intestinal hormones response (Slavin, 2005). However, because most clinical experiments do not distinguish between the different types of fiber, it is not totally clear if a specific fiber, such as beta-glucan, is effective in reducing body weight (Kim et al., 2006).

Three types of viscous fibers, pectin, alginate and cereal beta-glucan, were identified as potential satietyenhancing ingredients, because they appear to be more effective for appetite control (reduce subjective appetite, energy intake and/or body weight) (Slavin, 2005; Benelam, 2009; Wanders et al., 2011), especially when included in beverages or liquid test meals, ensuring that they are consumed in a fully hydrated form for higher efficacy (Ho et al., 2015). Pectins and most glucans were the types of fibers which exhibited the largest proportion of appetite-reducing effects over a 4-h time interval (Wanders et al., 2011; Blundell et al., 2010).

Studies with diabetic patients reported that the supplementation of beta-glucan through oats did not 
have significant effect on body weight (Ripsin et al., 1992; Pick et al., 1996). In another study, no significant effect on weight was observed in 68 hyperlipidemic patients that received high fiber (beta-glucan) diet compared with a control group who received normal diet (Jenkins et al., 2002).

In a systematic review, the percentage of treatments comparing the effects of fiber consumption with controls that significantly reduced subjective appetite rating was $39 \%$. The percentage that significantly reduced food or energy intake was $22 \%$. The satiety-enhancing effects of beta-glucan, lupin kernel fiber, rye bran, whole grain rye, or a mixed high-fiber diet were supported in more than one publication (Clark and Slavin, 2013).

Unfortunately, some studies do not provide clear and precise information or conclusion regarding the effect on weight, but some of them have provided a good perspective about this parameter. More data on the effect of dietary or supplementary beta-glucan on weight need to be developed (Kim et al., 2006).

\section{Immunomodulatory Activity of Beta- Glucans}

Beta-glucans from fungal cell walls are linear polymers made up of glucose units $\beta(1-3)$-Dglucopyranosyl with $\beta(1-6)$ branches of different sizes that have immunomodulatory activity (Xiao et al., 2004; Sonck et al., 2010). They have been shown to be able to modulate the immune nonspecific response (Samuelsen et al., 2014), stimulating phagocytosis and production of proinflammatory cytokines (Vetvicka, 2011; Rubin-Bejerano et al., 2007).

The protective involvement of beta-glucans have been reported as non-specific immunomodulation, by engaging different pathways of the immune system. These pathways include activation of macrophages, stimulation of the reticulum endothelial system and natural killer cell activation. By the other hand, the specific immunomodulation of beta-glucans can activate the classical and alternative complement pathways, stimulate $\mathrm{T}$ cells and increase an antibody production (Zeković et al., 2005; Czop, 1986).

The immunological potency of beta-glucans also can be associated with their ability to activate leukocytes (Sandvik et al., 2007). It is assigned and dependent on the molecular mass, conformation, solubility and also the degree and position of its ramifications. In general, it has been suggested that beta-glucans of high molecular weight (more prevalent in nature) can directly activate leukocytes, stimulating their phagocytic and antimicrobial functions and also their cytotoxic activity (Akramiene et al., 2007). Beta-glucans of intermediate molecular weight have biological activity in vivo, but its cellular effects are less evident, while beta-glucans of low molecular weight are generally considered inactive (Akramiene et al., 2007).

Macrophages are the main and best-characterized targets for the beta-glucans that activate these cells increasing their size and number, stimulating Tumor Necrosis Factor (TNF) secretion and increasing the phagocytosis of antigens. The stimulation of macrophages occurs via Toll-Like receptor 2 and with beta-glucan, recruits Toll-Like receptors 2 and send signals to the production of TNF- $\alpha$ by pathway of the Nuclear Factor- k $\beta$ (NF-k $\beta$ ) (Zeković et al., 2005; Czop, 1986; Meira et al., 1996; Pivarcsi et al., 2003).

Beta-glucans solutions obtained from fungi, when administered orally, reduced alveolar bone loss in rats with gingival inflammation (Breivik et al., 2005). Besides, in another study with diabetic rats induced to a similar inflammatory challenge, daily doses of betaglucans, was effective in reducing alveolar bone loss both diabetics and non-diabetics animals. The treatment reduced the expression of $\mathrm{COX}-2$ and RANK-L and increased the OPG expression in animals with diabetes and periodontal disease. This result may indicate a modulatory action of beta-glucan directly on the immune system as well as its antiinflammatory effects (Silva et al., 2015).

Beta-glucans have been extensively used as a preventive agent against infections. In several experimental models, these compounds have shown protection against infections by bacteria and protozoa, as well as an improvement in antimicrobial efficiency in infections caused by resistant bacteria (Rice et al., 2005). The protective effect of beta-glucans has been shown in experimental infections with Leishmania major and L. donovani, Candida albicans, Toxoplasma gondii, Streptococcus suis, Plasmodium berghei, Staphylococcus aureus, Escherichia coli, Mesocestoidescorti, Trypanosomacruzi, Eimeria vermiformis and Bacillus anthracis (Vetvicka, 2011).

\section{Vaccine Adjuvants}

Vaccination is the main preventive strategy of public health to populations worldwide, especially those more vulnerable to some infectious diseases and challenging pathogens (Di Pasquale et al., 2015). Some vaccines generate an adaptive immune response stimulating the immune system by using an antigen pathogen and/or activating the antigen present in cells. However, the use of recombinant, highly purified or synthetic antigenic determinants (epitopes) may have diminished immunostimulatory action when compared to vaccines containing living organisms. The approach used for decades to enhance the immunogenicity of the purified antigens resides in the use of adjuvants (Petrovsky and Aguilar, 2004; Di Pasquale et al., 2015). 
New technologies have been employed both in vaccines development and selection of powerful adjuvants. The adequate combination of the antigen and adjuvant may contribute either to the initial innate immune response and efficacy of the downstream adaptive immune response (Cordeiro et al., 2015). Adjuvants may be bacteria derived, liposome, aluminum salts, emulsions, tensoactives and carbohydrate based. Polysaccharides like glucans, dextrans, lentinans, galactomannans and glucomannans have been described as adjuvants (Di Pasquale et al., 2015). The mechanism described for these carbohydrates action as adjuvants involves the free-cellular toxicity response enhancement promoted by gamma inulin. However, as a complex carbohydrate, some polysaccharides based adjuvants may be metabolized to fructose and glucose reducing its efficacy (Petrovsky and Aguilar, 2004).

As beta-glucans are present in some bacteria, yeast and seaweed cell walls (Goodridge et al., 2009), it led to the exploration of these polysaccharides as immunostimulatory agents of the Pattern Recognition Receptors (PRRs) (Soltanian et al., 2009). Used as adjuvant, beta-glucans can deliver the antigen into cells and induce an antigen-specific immune response (Temizoz et al., 2016).

Intervention of beta glucans in immunity is mainly due to their interaction with specific cell receptors. CR3 (complement receptor), present in myeloid cells such as macrophages, Dendritic Cells (DCs) and NK cells, was the first receptor described for the recognition of betaglucans (Cordeiro et al., 2015).

The most studied beta-glucan receptor Dectin-1 is a type II transmembrane protein present in myeloid cells. The interaction of this receptor with betaglucans adjuvants induce the production of Reactive Oxygen Species (ROS), internalization of pathogens (Goodridge et al., 2009; Lipinski et al., 2013; Mochizuki and Sakurai, 2011), pro-inflammatory cytokines production, via the spleen tyrosine kinase (Syk)/NFkB pathway (Temizoz et al., 2016). This interaction also allowed the use of beta-glucans for the enhancement of immune responses triggering also the internalization of pathogens via phagocytosis (Cordeiro et al., 2015).

Influenza A virus is a dangerous pathogen and its H5N1 subtype can be transmitted directly from domestic fowls to humans leading to respiratory diseases and even death. Vaccination is the preventive approach to avoid seasonal pandemia, however, the use of adjuvants is important for vaccine effectiveness. Wang et al. (2016) showed that Saccharomyces cerevisiae had effects on the in vitro splenic lymphocyte cells of mice, promoting significantly lymphocyte proliferation singly or synergistically with Con A and LPS and stimulated the cells to secrete IL-2 and INF- $\gamma$. The same study evaluated the adjuvant activity of Saccharomyces cerevisiae in BALB/c mice inoculated with inactivated $\mathrm{H} 5 \mathrm{~N} 1$ vaccine in vivo, showing that Saccharomyces cerevisiae could significantly enhance lymphocyte proliferation, effectively increase the percentage of CD4+ T cells, decrease the percentage of CD8 $+\mathrm{T}$ cells and elevate the $\mathrm{CD} 4+/ \mathrm{CD} 8+$ ratio; enhance the $\mathrm{HI}$ antibody title and promote the production of IL-2, INF-, IL-4 and IL6 at medium level. These results indicated that sulfated glucan showed an excellent adjuvant effect on $\mathrm{H} 5 \mathrm{~N} 1$ vaccine in a mice model.

Beta-glucans from Saccharomyces cerevisiaeare important bioactive compounds for animal and human health, but its low solubility has led to some issues. Sulfate modification could improve its solubility and change its bioactivities. Sulfated yeast glucan could stimulate animal cells proliferation, promote cytokine secretion and enhance antibody titer of vaccine (Wang et al., 2016).

Dube et al. (2014) used chitosan-coated PLGA nanoparticles functionalized with 1,3-beta-glucan from Euglena gracilis for Dectin-1 targeting and reported an increased intracellular delivery of the encapsulated antituberculosis drug, enhanced pro-inflammatory reaction with relevant production of reactive oxygen and nitrogen species (Cordeiro et al., 2015). It is important to notice that beta-glucan adjuvant properties are different between each other, depending on many configurations of molecular structures, size and branches responsible for the differences (Soltanian et al., 2009; Adams et al., 2008; Barsanti et al., 2011; Sletmoen and Stokke, 2008).

Overall, beta-glucans present interesting immunomodulating properties as adjuvants for vaccine development and further research should test the limits for its applications.

\section{Antitumor Activity}

Beta-glucans have been therapeutically used as antitumor agents. These compounds can exercise their functions both within tumor microenvironments and systemically. This can occur by activation or recruitment of immune effectors cells in tumors or increasing the adaptive immune responses stimulated by concomitant immunotherapy (Barton et al., 2016). Thus, beta-glucans act as potent immunostimulant, stimulating the innate and adaptive immune response, which contributes to their antitumor properties (Tian et al., 2013). In addition, these polysaccharides have been described as biological response modifiers with antitumor properties which lead to potent immune responses through its recognition by a variety of pattern recognition receptors on dendritic cells, macrophages and neutrophils. The activation of these cells triggers adaptive immune cell responses, such 
as CD4, CD8, T cells and B cells, resulting in inhibition of tumor growth and metastasis (Albeituni and Yan, 2013; Yoon et al., 2013).

Numerous studies have highlighted the importance of these assets as effective contributors in anticancer therapies. A study in mice with mammary tumors showed the effectiveness of oral use of beta-glucans as an adjuvant for monoclonal antibody antitumor in cancer immunotherapy, activating the Th1 response which promotes the activity of cytotoxic $\mathrm{T}$ lymphocyte, resulting in a more effective way to remove tumors (Baran et al., 2007).

According to Hong et al. (2003) multiple tumor models were induced in mice that were subjected to treatments with antitumor antibodies, beta-glucans and beta-glucan combined with antitumor monoclonal antibodies. The combined treatment led to a greater tumor regression in all models that included breast carcinoma and liver tumors, indicating that the therapeutic efficacy of the antitumor antibodies can be significantly enhanced by concurrent administration of beta-glucan. This action is due to the recruitment of granulocytes as tumor killer cells which are powered by recognition of the complement system via CR3 (Hong et al., 2003).

Other pre-clinical studies in mice revealed that betaglucan can improve anti-tumor immune responses by activating the complement system and recruiting tumoricidal granulocytes in addition to the activation of the Dectin-1 signaling pathway. On the other hand, although some clinical trials, conducted in Japan and China, demonstrated the anti-tumor effect of beta-glucan in carcinoma and leukemia patients, clinical studies are still scarce (Temizoz et al., 2016).

A short-term clinical study was conducted in which female patients with breast cancer at an advanced stage receiving daily doses of beta-glucan orally for 15 days. The cancer patients were compared with healthy patients/control group. Despite a relatively low initial white blood cell count, the administration of beta-glucan stimulated the proliferation and activation of monocytes in patients with advanced breast cancer (Demir et al., 2007).

Generally, a variety of species of edible fungi containing beta-glucan have been widely used as assets with potential anticancer activity (Chan et al., 2009). Fractions of Maitake mushrooms decreased the size of lung, liver and breast cancer when combined with chemotherapy. On the other hand, these effects were less evident in patients with leukemia, stomach and brain cancer which were also treated with Maitake mushroom extracts (Kodama et al., 2002; 2003). The D-fraction Maitake combined with the agonist nine of the Toll-like receptor increased the expression of dendritic cell maturation markers and also, increased the interleukin12 in dendritic cells, but did not increase the production of interleukin-10. These results provide the basis for a potent antitumor therapy using a combination of immunological agents for future immunotherapy clinical studies in the patients (Masuda et al., 2015).

\section{Conclusion}

Beta-glucans from yeast $(\beta-1,3 / 1,6)$ have a higher immunomodulatory activity, while those from plants and bacteria $(\beta-1,3 / 1,4)$ have characteristics that confer greater metabolic potential. The low incidence of collateral effects associated with the use of beta-glucans should be considered for its inclusion in a range of immune prevention and therapies.

\section{Acknowledgment}

The authors would like to thank the Research Support Foundation of the State of Minas Gerais (Fundação de Amparo à Pesquisa do Estado de Minas Gerais FAPEMIG), National Council for Scientific and Technological Development (Conselho Nacional de DesenvolvimentoCientífico e Tecnológico - CNPq) and Coordination for the Improvement of Higher Education Personnel (Coordenação de Aperfeiçoamento de Pessoal de Nível Superior - CAPES) for the support provided.

\section{Author's Contributions}

The authors contributed equally to this work. All authors read and approved the final manuscript.

\section{Ethics}

Not applicable.

\section{References}

Adams, E.L., P.J. Rice, B. Graves, H.E. Ensley and H. Yu et al., 2008. Differential high-affinity interaction of dectin-1 with natural or synthetic glucans is dependent upon primary structure and is influenced by polymer chain length and side-chain branching. J. Pharmacol. Exp. Ther., 325: 115-123. DOI: 10.1124/jpet.107.133124

Akramiene, D., A. Kondrotas, J. Didziapetriene and E. Kevelaitis, 2007. Effects of beta-glucans on the immune system. Medicina (Kaunas), 43: 597-606. PMID: 17895634

Albeituni, S.H. and J. Yan, 2013. The effects of $\beta$ glucans on dendritic cells and implications for cancer therapy. Anticancer Agents Med. Chem., 13: 689-698. DOI: 10.2174/1871520611313050003

Alfieri, M.A., J. Pomerleau, D.M. Grace and L. Anderson, 1995. Fiber intake of normal weight, moderately obese and severely obese subjects. Obes. Res., 3: 541-547. DOI: 10.1002/j.1550-8528.1995.tb00188.x 
de Araújo, T.V., E.F. Andrade, R.V. Lobato, D.R. Gomes and N.F. de Sousa et al., 2016. Effects of betaglucans ingestion (Saccharomyces cerevisiae) on metabolism of rats receiving high-fat diet. J. Anim. Physiol. Anim. Nutr. DOI: 10.1111/jpn. 12452

Baran, J., D.J. Allendorf, F. Hong and G.D. Ross, 2007. Oral beta-glucan adjuvant therapy converts nonprotective Th2 response to protective Th1 cellmediated immune response in mammary tumorbearing mice. Folia Histochem. Cytobiol., 45: 107-114. PMID: 17597024

Barsanti, L., V. Passarelli, V. Evangelista, A.M. Frassanito and P. Gualtieri, 2011. Chemistry, physicochemistry and applications linked to biological activities of $\beta$-glucans. Nat. Prod. Rep., 28: 205-230. DOI: $10.1039 / \mathrm{C} 0 \mathrm{NP} 00018 \mathrm{C}$

Barton, C., K. Vigor, R. Scott, P. Jones and H. Lentfer et al., 2016. Beta-glucan contamination of pharmaceutical products: How much should we accept? Cancer Immunol. Immunother., 65: 1289-1301. DOI: 10.1007/s00262-016-1875-9

Battilana, P., K. Ornstein, K. Minehira, J.M. Schwarz and K. Acheson et al., 2001. Mechanisms of action of beta-glucan in postprandial glucose metabolism in healthy men. Eur. J. Clin. Nutr., 55: 327-333. DOI: $10.1038 /$ sj.ejen. 1601160

Benelam, B., 2009. Satiation, satiety and their effects on eating behaviour. Nutr. Bull., 34: 126-173. DOI: $10.1111 /$ j.1467-3010.2009.01753.x

Blundell, J., C. de Graaf, T. Hulshof, S. Jebb and B. Livingstone et al., 2010. Appetite control: Methodological aspects of the evaluation of foods. Obes. Rev., 11: 251-270. DOI: $10.1111 /$ j.1467-789X.2010.00714.X

Bohn, J.A. and J.N. BeMiller, 1995. ( $1 \rightarrow 3)-\beta-d-G l u c a n s$ as biological response modifiers: A review of structurefunctional activity relationships. Carbohydr. Polym., 28: 3-14. DOI: 10.1016/0144-8617(95)00076-3

Breivik, T., P.K. Opstad, R. Engstad, G. Gundersen and P. Gjermo et al., 2005. Soluble beta-1,3/1,6-glucan from yeast inhibits experimental periodontal disease in Wistar rats. J. Clin. Periodontol., 32: 347-352. DOI: $10.1111 / \mathrm{j} .1600-051 X .2005 .00672 . \mathrm{X}$

Chan, G., W. Chan, D. Sze, 2009. The effects of $\beta$ glucan on human immune and cancer cells. J. Hematol. Oncol., 2: 25-25.

DOI: $10.1186 / 1756-8722-2-25$

Chen, J., X.D. Zhang and Z. Jiang, 2013. The application of fungal $\beta$-glucans for the treatment of colon cancer. Anticancer Agents Med. Chem., 13: 725-730. PMID: 23293888

Choi, J.S., H. Kim, M.H. Jung, S. Hong and J. Song, 2010. Consumption of barley beta-glucan ameliorates fatty liver and insulin resistance in mice fed a high-fat diet. Mol. Nutr. Food Res., 54: 1004-1013. DOI: 10.1002/mnfr.200900127
Clark, M.J. and J.L. Slavin, 2013. The effect of fiber on satiety and food intake: A systematic review. J. Am. Coll. Nutr., 32: 200-211. DOI: $10.1080 / 07315724.2013 .791194$

Collins, S. and G. Reid, 2016. Distant site effects of ingested prebiotics. Nutrients, 8: 523-523. DOI: $10.3390 /$ nu8090523

Cordeiro, A.S., M.J. Alonso and M. de la Fuente, 2015. Nanoengineering of vaccines using natural polysaccharides. Biotechnol. Adv., 33: 1279-1293. DOI: $10.1016 /$ j.biotechadv.2015.05.010

Czop, J.K., 1986. The role of $\beta$-glucan receptors on blood and tissue leukocytes in phagocytosis and metabolic activation. Pathol. Immunopathol. Res., 5: 286-296. DOI: 10.1159/000157022

DeFronzo, R.A., 2004. Pathogenesis of type 2 diabetes mellitus. Med. Clin. North. Am., 88: 787-835.

DOI: $10.1016 /$ j.mcna.2004.04.013

Demir, G., H.O. Klein, N. Mandel-Molinas and N. Tuzuner, 2007. Beta glucan induces proliferation and activation of monocytes in peripheral blood of patients with advanced breast cancer. Int. Immunopharmacol., 7: 113-116. DOI: 10.1016/j.intimp.2006.08.011

Dong, J., F. Cai, R. Shen and Y. Liu, 2011. Hypoglycaemic effects and inhibitory effect on intestinal disaccharidases of oat beta-glucan in streptozotocin-induced diabetic mice. Food Chem., 129: 1066-1071. DOI: 10.1016/j.foodchem.2011.05.076

Dube, A., J.L. Reynolds, W.C. Law, C.C. Maponga and P.N. Prasad et al., 2014. Multimodal nanoparticles that provide immunomodulation and intracellular drug delivery for infectious diseases. Nanomedicine Nanotechnol. Biol. Med., 10: 831-838. DOI: 10.1016/j.nano.2013.11.012

Fazeli Farsani, S., M.P. van der Aa, M.M.J. van der Vorst, C.A.J. Knibbe and A. de Boer, 2013. Global trends in the incidence and prevalence of type 2 diabetes in children and adolescents: A systematic review and evaluation of methodological approaches. Diabetologia, 56: 1471-1488. DOI: $10.1007 / \mathrm{s} 00125-013-2915-\mathrm{z}$

Francelino Andrade, E., R. Vieira Lobato, T. Vasques Araújo, M. Gilberto Zangerônimo and R. Vicente Sousa et al., 2014. Effect of beta-glucans in the control of blood glucose levels of diabetic patients: A systematic review. Nutr. Hosp., 31: 170-177. DOI: $10.3305 / \mathrm{nh} .2015 .31 .1 .7597$

Gacto, M., J. Vicente-Soler, J. Cansado and T.G. Villa, 2000. Characterization of an extracellular enzyme system produced by Micromonospora chalcea with lytic activity on yeast cells. J. Applied Microbiol., 88: 961-967. DOI: $10.1046 /$ j.1365-2672.2000.01065.x 
Gao, R., Y. Wang and Z. Wu, J. Ming and G. Zhao, 2012. Interaction of barley $\beta$-glucan and tea polyphenols on glucose metabolism in streptozotocin-induced diabetic rats. J. Food Sci., 77: H128-34. DOI: $10.1111 / j .1750-3841.2012 .02688 . x$

Goodridge, H.S., A.J. Wolf and D.M. Underhill, 2009. $\beta$-glucan recognition by the innate immune system. Immunol. Rev., 230: 38-50. DOI: $10.1111 / \mathrm{j} .1600-065 X .2009 .00793 . \mathrm{x}$

Hanada, N., T. Katayama and A. Kunimori, 1993. Four different types of glucans synthesised by glucosyltransferases from Streptococcus sobrinus. Microbios. 73: 23-35.

Harnack, U., K. Eckert and G. Pecher, 2011. Beta-(1-3),(16)-D-glucan enhances the effect of low-dose cyclophosphamide treatment on A20 lymphoma in mice. Anticancer Res., 31: 1169-1172. PMID: 21508361

Ho, I.H.H., L. Matia-Merino and L.M. Huffman, 2015. Use of viscous fibres in beverages for appetite control: A review of studies. Int. J. Food. Sci. Nutr., 66: 479-490. DOI: 10.3109/09637486.2015.1034252

Hong, F., R.D. Hansen, J. Yan, D.J. Allendorf and J.T. Baran et al., 2003. Beta-glucan functions as an adjuvant for monoclonal antibody immunotherapy by recruiting tumoricidal granulocytes as killer cells. Cancer Res., 63: 9023-9031. PMID: 14695221

Jelsma, J. and D.R. Kreger, 1975. Ultrastructural observations on $(1 \rightarrow 3)-\beta$-D-glucan from fungal cellwalls. Carbohydr. Res., 43: 200-203. DOI: 10.1016/S0008-6215(00)83988-9

Jenkins, A.L., D.J.A. Jenkins, U. Zdravkovic, P. Würsch and V. Vuksan, 2002. Depression of the glycemic index by high levels of beta-glucan fiber in two functional foods tested in type 2 diabetes. Eur. J. Clin. Nutr., 56: 622-628. DOI: 10.1038/sj.ejen.1601367

Kim, S.Y., H.J. Song, Y.Y. Lee, K.H. Cho and Y.K. Roh, 2006. Biomedical issues of dietary fiber $\beta$ glucan. J. Korean Med. Sci., 21: 781-789. DOI: $10.3346 / \mathrm{jkms} .2006 .21 .5 .781$

Kim, Y.W., K.H. Kim, H.J. Choi and D.S. Lee 2005. Anti-diabetic activity of beta-glucans and their enzymatically hydrolyzed oligosaccharides from Agaricus blazei. Biotechnol. Lett., 27: 483-487. DOI: $10.1007 / \mathrm{s} 10529-005-2225-8$

Kimm, S.Y., 1995. The role of dietary fiber in the development and treatment of childhood obesity. Pediatrics, 96: 1010-1014. PMID: 7494672

King, D.E., A.G. Mainous, B.M. Egan, R.F. Woolson and M.E. Geesey, 2005. Fiber and C-reactive protein in diabetes, hypertension and obesity. Diabetes Care, 28: 1487-1489. DOI: $10.2337 /$ diacare.28.6.1487

Kodama, N., K. Komuta and H. Nanba, 2002. Can maitake MD-fraction aid cancer patients? Altern. Med. Rev., 7: 236-239. PMID: 12126464
Kodama, N., K. Komuta and H. Nanba, 2003. Effect of Maitake (Grifola frondosa) D-Fraction on the activation of NK cells in cancer patients. J. Med. Food., 6: 371-377. DOI: $10.1089 / 109662003772519949$

Li, J., Y. Aizawa, K. Hiramoto, E. Kasahara and D. Tsuruta et al., 2015. Anti-inflammatory effect of water-soluble complex of 1'-acetoxychavicol acetate with highly branched $\beta$-1,3-glucan on contact dermatitis. Biomed. Pharmacother., 69: 201-207. DOI: $10.1016 /$ j.biopha.2014.11.026

Liatis, S., P. Tsapogas, E. Chala, C. Dimosthenopoulos and K. Kyriakopoulos et al., 2009. The consumption of bread enriched with betaglucan reduces LDL-cholesterol and improves insulin resistance in patients with type 2 diabetes. Diabetes Metab., 35: 115-120.

DOI: 10.1016/j.diabet.2008.09.004

Lipinski, T., A. Fitieh, J. St. Pierre, H.L. Ostergaard and D.R. Bundle et al., 2013. Enhanced immunogenicity of a tricomponent mannan tetanus toxoid conjugate vaccine targeted to dendritic cells via dectin-1 by incorporating $\beta$ glucan. J. Immunol., 190: 4116-4128. DOI: $10.4049 /$ jimmunol.1202937

Lissner, L., A.K. Lindroos and L.Sjöström, 1998. Swedish Obese Subjects (SOS): An obesity intervention study with a nutritional perspective. Eur. J. Clin. Nutr., 52: 316-322. DOI: $10.1038 /$ sj.ejcn. 1600567

Liu, S., 2003. Whole-grain foods, dietary fiber and type 2 diabetes: Searching for a kernel of truth. Am. J. Clin. Nutr., 77: 527-529. PMID: 12600838

Liu, S., J.E. Buring, H.D. Sesso, E.B. Rimm and W.C. Willett et al., 2002. A prospective study of dietary fiber intake and risk of cardiovascular disease among women. J. Am. Coll. Cardiol., 39: 49-56. DOI: 10.1016/S0735-1097(01)01695-3

Lo, H.C., F.A. Tsai, S.P. Wasser, J.G. Yang and B.M. Huang, 2006. Effects of ingested fruiting bodies, submerged culture biomass and acidic polysaccharide glucuronoxylomannan of Tremella mesenterica Retz.:Fr. on glycemic responses in normal and diabetic rats. Life Sci., 78: 1957-1966. DOI: $10.1016 /$ j.lfs.2005.08.033

Malandrino, N. and R.J. Smith, 2011. Personalized medicine in diabetes. Clin. Chem., 57: 231-240. DOI: $10.1373 /$ clinchem.2010.156901

Masuda, Y., D. Nawa, Y. Nakayama, M. Konishi and H. Nanba, 2015. Soluble $\beta$-glucan from Grifola frondosa induces tumor regression in synergy with TLR9 agonist via dendritic cell-mediated immunity. J. Leukoc. Biol., 98: 1015-1025. DOI: $10.1189 / \mathrm{jlb} .1 \mathrm{~A} 0814-415 \mathrm{RR}$ 
Meira, D.A., P.C. Pereira, J. Marcondes-Machado, R.P. Mendes and B. Barraviera et al., 1996. The use of glucan as immunostimulant in the treatment of paracoccidioidomycosis. Am. J. Trop. Med. Hyg., 55: 496-503. PMID: 8940980

Miranda-Nantes, C.C.B.O., E.A.I. Fonseca, C.T.B.V. Zaia, C.T.B.V. Zaia and R.F.H. Dekker et al., 2011. Hypoglycemic and Hypocholesterolemic effects of botryosphaeran from Botryosphaeria rhodina MAMB-05 in Diabetes-Induced and Hyperlipidemia Conditions in Rats. Mycobiology, 39: 187-193.

DOI: 10.5941/MYCO.2011.39.3.187

Mochizuki, S. and K. Sakurai, 2011. Dectin-1 targeting delivery of TNF- $\alpha$ antisense ODNs complexed with $\beta$-1,3-glucan protects mice from LPS-induced hepatitis. J. Control Release, 151: 155-161.

DOI: 10.1016/j.jconrel.2011.01.026

Di Pasquale, A., S. Preiss, F. Tavares Da Silva and N. Garçon, 2015. Vaccine Adjuvants: From 1920 to 2015 and Beyond. Vaccines, 3: 320-343.

DOI: $10.3390 /$ vaccines 3020320

De Paula, A.C.C.F.F., R.V. Sousa, R.C.L. FigueiredoRibeiro and M.S. Buckeridge, 2005. Hypoglycemic activity of polysaccharide fractions containing betaglucans from extracts of Rhynchelytrum repens (Willd.) C.E. Hubb., Poaceae. Braz. J. Med. Biol. Res., 38: 885-893. PMID: 15933782

Petrovsky, N. and J.C. Aguilar, 2004. Vaccine adjuvants: Current state and future trends. Immunol. Cell Biol., 82: 488-496. DOI: 10.1111/j.0818-9641.2004.01272.x

Pick, M.E., Z.J. Hawrysh, M.I. Gee, E. Toth and M.L. Garg et al., 1996. Oat bran concentrate bread products improve long-term control of diabetes: A pilot study. J. Am. Diet Assoc., 96: 1254-1261. DOI: 10.1016/S0002-8223(96)00329-X

Pivarcsi, A., L. Bodai, B. Réthi, A. Kenderessy-Szabó and A. Koreck et al., 2003. Expression and function of Toll-like receptors 2 and 4 in human keratinocytes. Int. Immunol., 15: 721-730. DOI: 10.1093/intimm/dxg068

Rahar, S., G. Swami, N. Nagpal, M.A. Nagpal and G.S. Singh, 2011. Preparation, characterization and biological properties of $\beta$-glucans. J. Adv. Pharm. Technol. Res., 2: 94-103.

DOI: $10.4103 / 2231-4040.82953$

Reyna, N.Y., C. Cano, V.J. Bermúdez, M.T. Medina and A.J. Souki et al., 2003. Sweeteners and beta-glucans improve metabolic and anthropometrics variables in well controlled type 2 diabetic patients. Am. J. Ther., 10: 438-443.

DOI: $10.1097 / 00045391-200311000-00010$

Rice, P.J., E.L. Adams, T. Ozment-Skelton, A.J. Gonzalez and M.P. Goldman et al., 2005. Oral delivery and gastrointestinal absorption of soluble glucans stimulate increased resistance to infectious challenge. J. Pharmacol. Exp. Ther., 314: 1079-1086. DOI: $10.1124 /$ jpet.105.085415
Ripsin, C.M., J.M. Keenan, D.R. Jacobs, P.J. Elmer and R.R. Welch et al., 1992. Oat products and lipid lowering. A meta-analysis. JAMA, 267: 3317-25. DOI: 10.1001/jama.1992.03480240079039

Rolin, D.B., P.E. Pfeffer, S.F. Osman, B.S. Szwergold and F. Kappler et al., 1992. Structural studies of a phosphocholine substituted $\beta-(1,3) ;(1,6)$ macrocyclic glucan from Bradyrhizobium japonicum USDA 110. Biochim. Biophys. Acta, 1116: 215-225. DOI: 10.1016/0304-4165(92)90014-L

Rop, O., J. Mlcek and T. Jurikova, 2009. Beta-glucans in higher fungi and their health effects. Nutr. Rev., 67: 624-631. DOI: 10.1111/j.1753-4887.2009.00230.x

Rubin-Bejerano, I., C. Abeijon, P. Magnelli, P. Grisafi and G.R. Fink, 2007. Phagocytosis by human neutrophils is stimulated by a unique fungal cell wall component. Cell Host Microbe, 2: 55-67. DOI: 10.1016/j.chom.2007.06.002

Ruthes, A.C., E.R. Carbonero, M.M. Córdova, C.H. Baggio and A.R.S. Santos et al., 2013. Lactarius rufus $(1 \rightarrow 3),(1 \rightarrow 6)-\beta$-D-glucans: Structure, antinociceptive and anti-inflammatory effects. Carbohydr. Polym., 94: 129-316. DOI: 10.1016/j.carbpol.2013.01.026

Samuelsen, A.B.C., J. Schrezenmeir and S.H. Knutsen, 2014. Effects of orally administered yeast-derived beta-glucans: A review. Mol. Nutr. Food Res., 58: 183-193. DOI: $10.1002 / \mathrm{mnfr} .201300338$

Sandvik, A., Y.Y. Wang, H.C. Morton, A.O. Aasen and J.E. Wang et al., 2007. Oral and systemic administration of $\beta$-glucan protects against lipopolysaccharide-induced shock and organ injury in rats. Clin. Exp. Immunol., 148: 168-177. DOI: $10.1111 / \mathrm{j} .1365-2249.2006 .03320 . \mathrm{x}$

Schalkwijk, C.G. and C.D.A. Stehouwer, 2005. Vascular complications in diabetes mellitus: The role of endothelial dysfunction. Clin. Sci. (Lond.), 109: 143-159. DOI: $10.1042 / \mathrm{CS} 20050025$

Schneeman, B.O., 1987. Dietary fiber and gastrointestinal function. Nutr. Rev., 45: 129-132. DOI: $10.1111 /$ j.1753-4887.1987.tb06343.x

Seino, Y., K. Nanjo, N. Tajima, T. Kadowaki and A. Kashiwagi et al., 2010. Report of the committee on the classification and diagnostic criteria of diabetes mellitus. J. Diabetes Investig., 1: 212-228. DOI: $10.1111 /$ j.2040-1124.2010.00074.x

Sener, G., E. Ekşioğlu-Demiralp, M. Cetiner, F. Ercan and B.Ç. Yeğen et al., 2006. Beta-glucan ameliorates methotrexate-induced oxidative organ injury via its antioxidant and immunomodulatory effects. Eur. J. Pharmacol., 542: 170-178. DOI: 10.1016/j.ejphar.2006.02.056

Silva, V.D.O., R.V. Lobato, E.F. Andrade, C.G. de Macedo and J.T.C. Napimoga et al., 2015. B-Glucans (Saccharomyces cereviseae) Reduce glucose levels and attenuate alveolar bone loss in diabetic rats with periodontal disease. PLoS One, 10: e0134742e0134742. DOI: 10.1371/journal.pone.0134742 
Silveira, M.L.L., F.R. Smiderle, C.P Moraes, D.G. Borato and C.H. Baggio et al., 2014. Structural characterization and anti-inflammatory activity of a linear $\beta$-D-glucan isolated from Pleurotus sajorcaju. Carbohydr. Polym., 113: 588-596. DOI: $10.1016 /$ j.carbpol.2014.07.057

Slavin, J.L., 2005. Dietary fiber and body weight. Nutrition, 21: 411-418. DOI: $10.1016 /$ j.nut.2004.08.018

Sletmoen, M. and B.T. Stokke, 2008. Higher order structure of $(1,3)-\beta$-D-glucans and its influence on their biological activities and complexation abilities. Biopolymers, 89: 310-321. DOI: 10.1002/bip.20920

Smeekens, S.P., M.S. Gresnigt, K.L. Becker, S.C. Cheng and S.A. Netea et al., 2015. An anti-inflammatory property of Candida albicans $\beta$-glucan: Induction of high levels of interleukin-1 receptor antagonist via a Dectin-1/CR3 independent mechanism. Cytokine, 71: 215-222. DOI: 10.1016/j.cyto.2014.10.013

Soltanian, S., E. Stuyven, E. Cox, P. Sorgeloos and P. Bossier, 2009. Beta-glucans as immunostimulant in vertebrates and invertebrates. Crit. Rev. Microbiol., 35: 109-138. DOI: $10.1080 / 10408410902753746$

Sonck, E., E. Stuyven, B. Goddeeris and E. Cox, 2010. The effect of $\beta$-glucans on porcine leukocytes. Vet. Immunol. Immunopathol., 135: 199-207. DOI: $10.1016 /$ j.vetimm.2009.11.014

Suchecka, D., J.P. Harasym, J. Wilczak, M. Gajewska and M. Oczkowski et al., 2015. Antioxidative and anti-inflammatory effects of high beta-glucan concentration purified aqueous extract from oat in experimental model of LPS-induced chronic enteritis. J. Funct. Foods, 14: 244-254.

DOI: $10.1016 /$ j.jff.2014.12.019

Sunil, C., S. Ignacimuthu and P. Agastian, 2011. Antidiabetic effect of Symplocos cochinchinensis (Lour.) S. Moore. in type 2 diabetic rats. J. Ethnopharmacol., 134: 298-304.

DOI: $10.1016 /$ j.jep.2010.12.018

Tappy, L., E. Gugolz and P. Wursch, 1996. Effects of breakfast cereals containing various amounts of $\beta$ glucan fibers on plasma glucose and insulin responses in NIDDM subjects. Diabetes. Care, 19: 831-834. DOI: 10.2337/diacare.19.8.831

Temizoz, B., E. Kuroda and K.J. Ishii, 2016. Vaccine adjuvants as potential cancer immunotherapeutics. Int. Immunol., 28: 329-338.

DOI: $10.1093 /$ intimm/dxw015

Tian, J., J. Ma, K. Ma, H. Guo and S.E. Baidoo et al., 2013. $\beta$-Glucan enhances antitumor immune responses by regulating differentiation and function of monocytic myeloid-derived suppressor cells. Eur. J. Immunol., 43: 1220-1230.

DOI: $10.1002 /$ eji.201242841
Tiwari, U. and E. Cummins, 2011. Meta-analysis of the effect of $\beta$-glucan intake on blood cholesterol and glucose levels. Nutrition, 27: 1008-1016.

DOI: $10.1016 /$ j.nut.2010.11.006

Tosh, S.M., 2013. Review of human studies investigating the post-prandial blood-glucose lowering ability of oat and barley food products. Eur. J. Clin. Nutr., 67: 310-317.

DOI: $10.1038 /$ ejen.2013.25

Túrmina, J., E. Carraro, M.A. Cunha, R.F.H. Dekker and A.M. Barbosa et al., 2012. Toxicological Assessment of $\beta$-(1à6)-Glucan (Lasiodiplodan) in Mice during a 28-Day Feeding Study by Gavage. Molecules, 17: 14298-14309.

DOI: $10.3390 /$ molecules 171214298

Vetvicka, V., 2011. Glucan-immunostimulant, adjuvant, potential drug. World. J. Clin. Oncol., 2: 115-119. DOI: 10.5306/WJCO.v2.i2.115

Vieira Lobato, R., V. De Oliveira Silva, E. Francelino Andrade, D. Ribeiro Orlando and M. Gilberto Zangeronimo, 2015. Metabolic Effects of $\beta$ glucans (Saccharomyces cerevisae) per os Administration in Rats with Streptozotocininduced Diabetes. Nutr. Hosp., 32: 256-264. DOI: $10.3305 / \mathrm{nh} .2015 .32 .1 .9013$

Volman, J.J., J.D. Ramakers and J. Plat, 2008. Dietary modulation of immune function by $\beta$-glucans. Physiol. Behav., 94: 276-284.

DOI: 10.1016/j.physbeh.2007.11.045

Vos, A.P., L. M'Rabet, B. Stahl, G. Boehm and J. Garssen et al., 2007. Immune-modulatory effects and potential working mechanisms of orally applied nondigestible carbohydrates. Crit. Ver. Immunol., 27: 97-140.

DOI: 10.1615/CRITREVIMMUNOL.V27.I2.10

Wanders, A.J., J.J.G.C. van den Borne, C. de Graaf, T. Hulshof, M.C. Jonathan et al., 2011. Effects of dietary fibre on subjective appetite, energy intake and body weight: A systematic review of randomized controlled trials. Obes. Ver., 12: 724-739. DOI: 10.1111/j.1467-789X.2011.00895.x

Wang, H., D. Weening, E. Jonkers, T. Boer, F. Stellaard et al., 2008. A curve fitting approach to estimate the extent of fermentation of indigestible carbohydrates. Eur. J. Clin. Invest., 38: 863-868. DOI: $10.1111 /$ j.1365-2362.2008.02030.x

Wang, M., L. Zhang, R. Yang, C. Fei and X. Wang et al., 2016. Improvement of immune responses to influenza vaccine $(\mathrm{H} 5 \mathrm{~N} 1)$ by sulfated yeast betaglucan. Int. J. Biol. Macromol., 93: 203-207. DOI: 10.1016/j.ijbiomac.2016.06.057

WHO, 2016. Global report on diabetes. World Heal Organ Geneva. 
Xiao, Z., C.A. Trincado and M.P. Murtaugh, 2004. $\beta$ Glucan enhancement of $\mathrm{T}$ cell IFN $\gamma$ response in swine. Vet. Immunol. Immunopathol., 102: 315-320. DOI: $10.1016 /$ j.vetimm.2004.09.013

Yoon, T.J., S. Koppula and K.H. Lee, 2013. The effects of $\beta$-glucans on cancer metastasis. Anticancer. Agents. Med. Chem., 13: 699-708.

DOI: $10.2174 / 1871520611313050004$
Zeković, D.B., S. Kwiatkowski, M.M. Vrvić, D. Jakovljević and C.A. Moran, 2005. Natural and modified $(1 \rightarrow 3)-\beta$-D-glucans in health promotion and disease alleviation. Crit. Rev. Biotechnol., 25: 205-230. DOI: 10.1080/07388550500376166 